\title{
LINGUISTICS AND THE NDEA
}

The recognition of language competence as an important element in national defence is the culmination of a sequence of events which, when looked at in retrospect, have a compelling logic behind them. Seven years ago the Modern Language Association began its foreign-language program, with the purpose of evaluating the place of foreign languages in American life and American education. One of the early activities of this program was the preparation, by Dr. William R. Parker, its director, of the UNESCO work paper entitled Foreign Language and the National Interest, a document designed to serve as the basis for community discussion groups. Finally in 1958, Congress finds "an insufficient proportion of our population educated...in modern foreign languages" and authorizes federal funds to the amount of some fifteen million dollars annually to "correct as rapidly as possible the existing imbalances in our educational programs." This, then, is the path of propulsion which placed the language gap right alongside the missile gap as a recognized educational need.

We have all learned, of course, to distinguish the linguistic scientist from the polyglot, and to discriminate proficiency in the practical command of language from the scientific analysis of language and languages. The NDEA, or at least those titles of it which apply to foreign-language study, are designed principally to increase language competence. What, then, is the role of linguistics in this national effort?

This question may best be answered in terms of Title VI, that portion of the act devoted wholly to language training. Foreign languages are also, or may be, part of the concern of Titles III and VII, but for the purposes of dealing with this question we may confine ourselves to the sixth section. of the act.

There are four different kinds of programs or activities supported by Title VI: language teachers' institutes, language and area centers, fellowships for language study, and language research. As we shall see, linguistics has a significant role to play in each. 
The language teachers' institutes are designed to prepare, or to improve the preparation of those who are engaged in the teaching of languages in the elementary or secondary schools. In them, attention is to be concentrated upon the new teaching methods and instructional materials. To the extent to which linguistics bears, or can be brought to bear, upon new methods and materials, and this is by no means inconsiderable, it has a place in the program of the institutes.

During the summer of 1959,925 teachers of elementary and secondary foreign languages participated in twelve summer institutes. Three times that number are planned for 1960 . With one exception, every summer institute included instruction in linguistics, either directly or indirectly in its program. Some institutes had as many as three or four nationally recognized linguistic scholars on their staffs. Looking into the future, we encounter two basic problems: (1) supplying competent linguists for thirty-six institutes; (2) developing courses that will be helpful to language teachers. Both of these are critical and need immediate attention.

An important purpose of the NDEA was to further the teaching of such modern for eign languages as are not generally taught in this country and to provide complementary studies in those foreign areas. Almost immediately upon passage of the act, Arabic, Chinese, Japanese, Russian, Hindi and Portuguese were recognized as top priority languages, and the nineteen centers established last year were confined chiefly to them. Since then a further list of approximately twenty second-priority languages has been compiled, and it is expected that these will figure to an increasing degree in the twenty-one additional institutes which will be approved for 1960-61.

It is assumed that in these centers, most of the language courses will be intensive in nature and that they will emphasize a spoken command of the language. The role of linguistics in educational programs of this kind has been firmly established ever since the World War II days of the Intensive Language Program of the ACLS. The linguist is just as important here as he ever was: in the formulation of the contrast between the native and the target languages, in the preparation of materials exploiting such contrasts, in devising tests, in making use of laboratory and other audio-aids.

Activities falling into these categories can be supported under the terms of section 602 of the act which authorizes research on more effective methods of teaching such languages and the development of specialized materials. Certainly a considerable amount of the research that linguists do can rcadily 
be justified under a broad interpretation of the act since the development of specialized materials necessarily depends on further advances in what might be called the pure science.

The largest research grant made thus far is for roughly $\$ 650,000$ to develop specialized training materials in some twenty-five Ural-Altaic languages and to conduct basic surveys and pertinent research dealing with the languages, areas, and countries. What this illustrates, if anything, is the value of careful research planning and coordination. A similar project for any one of the major language groups would have had an equal chance of acceptance, but none was presented.

Other on-going NDEA projects of interest to the linguist range from the preparation of contrastive structural studies of English vis-a-vis French, German, Italian, Russian, and Spanish, (Center for Applied Linguistics), to the development and modification of instruments for the electronic analysis of speech, applying them to the phonetic comparison of English with French, German, and Spanish (Pierre de Lattre, Colorado). Smaller grants provide for the development of teaching materials for Lomongo, (a Bantu language), for the preparation of $X$-ray sound motion picture films, for a linguistic and anthropological investigation of Kazakh.

No less than $\$ 4,000,000$ is due to be committed to research this year; how much of it can be reserved for linguistic research will depend upon the enterprise and imagination of the linguists themselves.

Finally, language and area centers need students, and a fellowship program has been devised to encourage and subsidize study in these fields. As is wholly proper the prime purpose of the fellowships is to provide teachers of these languages and to supply personnel for other services of a public nature demanding such linguistic competence. They are not designed to subsidize graduate study in linguistics per se. Nevertheless, to the degree that work in linguistics is necessary for potential teachers of the "exotic" languages, to that extent may it be legitimately included within the program.

In short, the NDEA in what is virtually a single package has provided a group of opportunities that linguists have been awaiting for years: the chance to apply linguistics to the teaching of the so-called common languages, the development of materials and basic research in the unusual languages, further exploration into mechanical aids to linguistic analysis, the development of contrastive structural studies-and most important of all, student aid. 
If the linguists fail to make the best of this situation, they may have to wait decades before another presents itself. If they fail to live up to the claims they have made for their science-often too vociferously and without due modesty and caution-they may have muffed the chance for once and all. It is no exaggeration to say that the NDEA has put linguistics squarely on the spot. "Put up or shut up" may be a crude phrase, but it describes the situation precisely.

Albert H. Marckwardt University of Michigan 